\title{
The Implications of Failing to Assist
}

\author{
Christian Barry* and Gerhard Øverland**
}

\begin{abstract}
In this essay we argue that an agent's failure to assist someone in need at one time can change the cost she can be morally required to take on to assist that same person at a later time. In particular, we show that the cost the agent can subsequently be required to take on to help the person in need can increase quite significantly, and can be enforced through the proportionate use of force. We explore the implications of this argument for the duties of the affluent to address global poverty.
\end{abstract}

Keywords: duties to assist; nonideal theory; global poverty; beneficence; enforcement of duties

Consider a simple case, explored by Peter Singer: a child is drowning but can be saved by a bystander (we'll call him Bill). ${ }^{1}$ The child is a total stranger to Bill and so is her family; Bill has not promised anyone that he will look after her; he occupies no specific role that requires him to save children or others in need. In short, Bill has no special or associationbased duties to her.

If Bill had contributed to the child's plight by intentionally shoving or coaxing her into the river, or had she ended up there through his recklessness or negligence, it is fairly uncontroversial that he would be morally required to take on a great deal of cost to save her. In this case his duty to assist the child would not be based merely on his ability to save her, but on his having contributed to her plight-a contribution-based duty. And if he did have a contribution-based duty to the child, he could in principle be compelled by others to make large sacrifices to save her, or could permissibly be harmed by others if this became necessary to save the child.

What if he lacked a contribution-based duty to her? In that case, any duty he has to the child is based simply on his ability to assist her at some cost-an assistance-based duty. The assistance-based duties of innocent bystanders, and what they can be compelled to do, are controver-

\footnotetext{
${ }^{1}$ Peter Singer, "Famine, Affluence, and Morality," Philosophy \& Public Affairs 1 (1972): 229-43, p. 231.

(c) Copyright 2014 by Social Theory and Practice, Vol. 40, No. 4 (October 2014): ???-???. DOI: ???
} 
sial. ${ }^{2}$ That is, while it seems clear that Bill has a duty to save the child when he first encounters her, in the sense that he is morally required to take on some cost to assist her, there is little agreement about just how much cost he is required to take on for this purpose.

For the purposes of this essay, we will not try to settle this controversy by establishing how demanding the assistance-based duties of innocent bystanders are in simple rescue cases like this one. We shall simply assume, as a great many people seem to do, that such assistance-based duties are initially not very demanding. That is, we shall assume that innocent bystanders are not (pace Singer and Unger) ordinarily required to take on a great deal of cost-sacrificing limbs, their homes, their retirement savings - to assist strangers when they become aware of their extreme need. Our aim will be to explore the implications of failing to assist when you can do so at low cost, for it is in this context that it seems least controversial that you have a duty to assist. We shall argue that an agent's failure to assist someone in need at one time can change the cost she can be morally required to take on to assist that same person at a later time. In particular, the cost the agent can subsequently be required to take on to help the person in need can increase quite significantly.

The debate about assistance-based duties has so far focused on trying to determine, at least roughly, the magnitude of the sacrifice that innocent bystanders are morally required to make when they encounter someone in desperate need, like the child in our case. This question is clearly of critical importance. ${ }^{3}$ But focusing on this question exclusively may risk occluding the fact that duties are not static but dynamic in their demands on the agents who bear them. Indeed, we shall argue that the fact that the cost that can be morally required of a person to save another in need is initially low cannot be used to infer that large sacrifices are not required of that person at some later point if this person has so far failed to assist the person in need. We shall also argue that when people fail to assist, this can significantly increase the cost others could permissibly impose on them in the future to help the person in need.

We develop our argument by considering variations on the simple rescue case with which we began. However, philosophers have been interested in such cases because, following Singer, they have thought that consideration of the duties of people like Bill may shed light on the

\footnotetext{
${ }^{2}$ The literature on duties to assist the poor abroad is vast. Some important contributions include: Singer, "Famine, Affluence, and Morality"; Peter Unger, Living High and Letting Die: Our Illusion of Innocence (New York: Oxford University Press, 1996); Liam Murphy, Moral Demands in Non-Ideal Theory (New York: Oxford University Press, 2000); and Garrett Cullity, The Moral Demands of Affluence (Oxford: Oxford University Press, 2004).

${ }^{3}$ For our own discussion of this issue, see Christian Barry and Gerhard Øverland, “How Much for the Child?” Ethical Theory and Moral Practice 16 (2013): 189-204.
} 
assistance-based duties of affluent people to poor people abroad. In the final section of this essay, we therefore consider the implications of our discussion of simple rescue cases for this more general issue.

\section{Assistance-Based Duties}

We shall limit ourselves to discussing sacrifices that bystanders are required to make to save children in extreme need. This is not because we think there is necessarily any difference between the required cost of saving healthy children (provided that they are not very young) and of saving healthy adults (provided that they are not very old). There is always some possibility that adults, unlike young children, can be held partially or fully responsible for being in a position where they need help, which many think should reduce the cost that people can be morally required to take on in order to save them.

To fix ideas and make our discussion more concrete, let us assume that agents have the following assistance-based duty:

Moderate: If you can prevent something very bad from happening to another person at no more than moderate cost to yourself (relative to what is at stake for the other person), then you ought to do it. ${ }^{4}$

According to Moderate, Bill has a duty to shoulder moderate cost in order to save the child from drowning at $t_{1}$, when he first becomes aware of the situation. What does moderate cost mean? Surely it means that to save the child he should be willing to get his clothes muddy and wet, perhaps even suffer some relatively minor injury, such as a broken limb. ${ }^{5}$ Suppose, however, that Bill could save the child by sacrificing significantly less than a broken limb, but fails to do so by $t_{2}$. What kind of sacrifice can he be required to make to save the child at a later time, $\mathrm{t}_{3}$, assuming that it is the last moment at which he can save her?

Some terminology will be helpful for understanding the different factors relevant to determining the level of sacrifice that people are required to make to assist others in need. We will refer to the cost that a person is

\footnotetext{
${ }^{4}$ Compare Scanlon: "If you are presented with a situation in which you can prevent something very bad from happening, or alleviate someone's dire plight, by making only a slight (or even moderate) sacrifice, then it would be wrong not to do so.” T.M. Scanlon, What We Owe to Each Other (Cambridge, Mass.: Harvard University Press, 1998), p. 224.

${ }^{5}$ This understanding of assistance-based duties, like others offered in the literature, is somewhat imprecise. But it seems artificial to make very precise ideas that seem, intuitively, to resist this. Regardless of whether we consider such duties to be more or less demanding, do we really have a clear idea about exactly how much cost we are required to take on to assist a person in need?
} 
morally required to shoulder for a particular purpose $\mathrm{X}$ as the required cost. The more demanding a duty is, the higher the required cost. We will call whatever cost a person would in practice need to shoulder in order to realize $\mathrm{X}$ the necessary cost. When you can save a person whom you have negligently knocked into the water just by leaning over and offering her your hand when doing so carries no risk of harm to yourself or others, the necessary cost of saving the person is low. But the required cost is high, since you would have a duty to do much more than offer your hand were that necessary to save her. Finally, we will refer to the cost that the person actually shoulders in attempting to realize $\mathrm{X}$ as the actual cost. The actual cost a person bears to save another person can of course be different from the necessary or required cost of saving her.

Let us also introduce (for simplicity and clarity) simple numerical cost units that denote decreases in well-being. Suppose that what is at stake is the life of the child, and that the required cost for the innocent bystander at $\mathrm{t}_{1}$ - the demands his duty to assist then imposes on him-is 10 cost units. Sometimes the necessary cost will exceed the required cost. In that case the agent will lack a duty to realize X. Should he nevertheless make the greater sacrifice (for instance, by taking on 15 cost units), he would have done more than his duty required of him. When (and only when) the necessary cost of realizing $\mathrm{X}$ is equal to or less than the required cost (of 10 units) does the person have a duty to realize $\mathrm{X}$.

When a person does not assist another at a particular time when he has a duty to save that person, we will call this an assistance failure. It would be a mistake to treat all assistance failures as morally on a par. The required cost for Bill to save the child at a later time would depend on various other features of the initial situation. There will almost always be some uncertainty about the risks involved in any attempt to assist others in need, its prospect of success, and the extent to which the situation is transparent to the agent. Suppose that Bill is unaware (and could not reasonably have been expected to be aware) that he can save the child at relatively low cost during the interval $t_{1}-t_{2}$. (Assume that Bill either knows nothing about the child's plight, or that he reasonably believes that any attempt to save her would be extremely risky and futile.) In these cases, it may seem implausible that his required cost at $t_{3}$ should exceed his required cost during the interval $t_{1}-t_{2}$. His assistance failure in this case would not only be nonculpable, he could not even know that he had a duty to take action to assist the child during this period.

Note, however, that regardless of whether or not Bill was aware of the situation and the risks involved in assisting the child, we cannot assume that he has failed in his duty to assist the child, simply because he failed 
to save her in the interval $\mathrm{t}_{1}-\mathrm{t}_{2} \cdot{ }^{6}$ Even if a duty to assist is owed to a particular individual (as seems plausible in this type of simple rescue case), it seems that there may be some discretion regarding when and how the duty-bearer discharges it. If, for example, all else is equal for the child, then Bill will have discharged his duty if he saves the child at any point during the period in which he can save her. So the question is not whether Bill's failure in his duty can increase the cost he is required to take on to save the child subsequently. The question is whether his failure to save initially, when he could assist at relatively low cost-his assistance failure-can change the cost he is required to take on at a later time.

Let us assume that the situation is completely transparent to Bill. He is fully aware that the expected costs to him involved in saving the child during $t_{1}-t_{2}$ are quite low, and that the likelihood of success is very high. He simply fails to save the child. Suppose then that at $t_{3}$ Bill can no longer save the child at the same (low) cost as previously, but can now save her at a higher cost - there is a bend in the river, and while Bill first came across the child in smooth water, she is now at a point where the river is pretty choppy. What then should his required cost be? In our view, Bill is now required to take on greater cost to save the child than he was previously. It could therefore now be the case that even though Bill was not required to bear the necessary cost of saving the child before $t_{3}$, he might at or after $t_{3}$ be required to do so due to his previous failure to assist.

Why should he be required to take on more cost at $t_{3}$ than he was previously? Well, because at $t_{3}$ Bill is at least partly responsible for the child's situation. He is responsible because the child's predicament at $t_{3}$ results in part from his earlier lack of assistance when the cost of doing so would not have exceeded the cost he had a duty to take on to save her. Whereas at $t_{1}$, it is not the case that the child's predicament depends in any way on Bill's having (so far) failed to discharge his duties to her, this is the case at $t_{3}$. Bill's decision not to assist the child during the interval $t_{1}-t_{2}$ has led to a situation where someone-either Bill or the child (or both in some measure)-must suffer a loss that is greater than anyone need have suffered previously. Since Bill had a duty to save the child when he decided not to, it seems fair that he now should be required to take on at least some of the additional cost to which his failure to assist has given rise.

\section{Other Factors}

We have claimed that an agent's duty to assist can become more demanding if he fails to assist at some point after the duty is triggered. But

\footnotetext{
${ }^{6} \mathrm{We}$ are grateful to an anonymous reviewer for pressing this point.
} 
how much additional sacrifice could be morally required? Various factors can make a difference. For example, it seems that there is a significant difference between failing to discharge one's duty when the necessary cost is 10 and failing to do so when the necessary cost is 0 , or very close to 0 . After all, in the latter case so very little was required for the agent to have discharged his duty in the first place. To capture this idea, we introduce a further notion, which we shall call assistance shortfalls. The magnitude of a person's assistance shortfall is determined by the difference between the necessary and required cost. When the required cost is 10 and the necessary cost is as close to 0 as it is possible to come-as when a person need only press a button to save the child-we have a maximum assistance shortfall of 10 . If on the other hand both the required cost and the necessary cost are 10, then there will be no assistance shortfall if the agent fails to save the child during the time interval in question. The agent has in this instance not done his duty, but the duty shortfall is 0 .

Significant assistance shortfalls occur in cases where there is a duty to assist and the necessary cost is small. For example, it may be the case that Bill could rescue the child from drowning simply by tossing a flotation device to her. Assume that the cost involved in saving the child by tossing such a device is 1 . If Bill fails to throw it, then his conduct would involve an assistance shortfall of 9. What implication would this assistance shortfall of 9 at $t_{2}$ have at a later time, $t_{3}$ ? Suppose that at $t_{3}$ there is no longer a flotation device that can be thrown to the child, and the river is now fairly choppy. (Imagine that Bill would at this point have to plunge into it to save the child, and should he do so is likely to suffer significant injury.) Consequently, the expected necessary cost of this later rescue operation is 15 . Does Bill have a duty to take on 15 cost units? (Note that the 15 units exceed by 5 units Bill's required cost at $t_{1}$.)

It seems quite plausible that Bill would indeed have a duty to bear additional cost at $t_{3}$ so long as he lacked a good excuse for having failed to save the child at very low cost by $t_{2}$. Things may be different, however, if after having failed to assist at $t_{2}$, Bill comes to regret his assistance failure. Suppose Bill repents his earlier failure to assist the child, and makes a sincere effort at $t_{3}$ to save her, bearing a cost up to the original required cost (10). He finds that taking on 10 cost units is now insufficient to save the child, but also recognizes that he can save the child if he takes on some additional cost (i.e., beyond the initial required cost of 10.) In this case, perhaps it is less obvious that Bill would be required to shoulder this additional cost. However, we also think that a person who sincerely repents his earlier conduct would likely consider himself to have a duty to bear additional cost due to his past failure. Surely it is a common experience to recognize that one "makes up for" prior treatment 
of another person-going out of one's way to do so if necessary. Indeed, one might say that willingness to take on additional cost in the present is a very good indicator of sincerely repenting one's failure to assist in the past.

But what if Bill's earlier failure to assist should not be considered a failure that he should morally repent? Suppose Bill knows that he can save the child during $t_{1}-t_{2}$ at low cost but resolves to save the child later, even though he knows that it will then be more costly to him. In that case, so long as this delay does not impose any additional risk of harm to the child nor cause her additional psychological distress by allowing her to remain at risk for longer, it may seem perfectly all right for him to defer performance of his duty. In this case, he would not need to repent. But of course the reason his earlier failure does not seem a moral failure is that he has already resolved to take on the additional cost later on. It would seem odd indeed for him to explain his earlier conduct by saying "I know I didn't save the child when it cost little for me to do so, but that is because I didn't mind the extra cost of saving her later and resolved to do so," but then claiming that at $t_{3}$ he no longer had a duty to save the child because the cost of doing so exceeded the required cost of his duty at $t_{1}$.

A straightforward proposal for calculating the increase in required cost for Bill resulting from his earlier failure to assist would be that he now has a duty to take on the combined required cost of his initial duty (10 units) and his assistance shortfall (9 units). On this proposal, Bill is required to bear 19 units if that is necessary to save the child. The necessary cost is now 15 units. Thus it does not exceed the required cost according to this proposal, and he has a duty to save the child.

Is the claim that he has a duty to take on as much as this (combined) cost plausible? Well, Bill did fail to save the child at very little cost (1 unit) when he was required to take on as much as 10 units. It might therefore be claimed that he now owes a moral debt to the child of 9 units as a result of his assistance failure. This seems to be the case whether or not he incurred this debt with the intention of discharging it later. And putting this specific debt aside, Bill still has an ordinary duty to bear the 10 units needed to assist the child at $t_{3}$ (just as would any innocent bystander who had not had an earlier opportunity to assist her).

However, the proposal that one should simply sum the units of the initial required cost and the assistance shortfall to determine an agent's required cost at the later time seems too crude. For one thing, it would have the counterintuitive implication that, in the case where an agent's assistance shortfall is zero, his failure to assist at an earlier time does not increase the cost he can be required to bear at a later time. If the required cost for Bill of saving the child at $t_{1}$ is to suffer as much as a broken arm, and the necessary cost of saving the child is to suffer a broken arm, then 
it seems that his failure to take on any cost to save the child during the interval $t_{1}-t_{2}$ should affect the cost he is required to take on at $t_{3}{ }^{7}$ Moreover, very large assistance shortfalls can seem to make much more difference than smaller assistance shortfalls-substantially more than the difference between the necessary costs involved in the shortfalls would suggest. Suppose, for example, Bill is sitting on the deck of his boat having his afternoon tea. He can save the child by pressing a button on the boat that will launch a lifesaving device to her. The button is within Bill's reach, and he could therefore save the child at close to zero cost. There are two possible reasons why he would not save the child in this case. Either he is unconcerned by the fate of the child (imagine that he prefers to continue sipping his tea uninterrupted) or he is concerned but prefers to save her later.

Principles of assistance-based duties like Moderate would not initially require that Bill make very large sacrifices to save the child from drowning in the river. But it seems that his initial failure to save the child at nearly zero cost by pressing a button should increase quite significantly his required cost to save the child at a later time, given the magnitude of his assistance shortfall. That is, the required cost at the later time would be more than the initial required cost summed with the assistance shortfall. This seems plausible even if his assistance failure does not seem wrong (in the event that he has resolved to save the child later, and his doing so imposes no additional risk on her nor causes her additional harm). If Bill does not press the button to prevent the child's death, then he should be committed to bearing a great deal more than 19 units to save the child at a later point, should that turn out to be necessary.

What would the magnitude of the increase in required cost be? In the next section we explore this question by considering the amount of cost that others could permissibly impose on Bill to compel him to save the child without violating his rights. Before proceeding, however, let us consider if the actual cost that agents take on to assist is pertinent to the required cost of duties arising from assistance failures.

Imagine that in our initial scenario, Lisa is present, and she can also save the child. Lisa attempts a rescue mission, while Bill does not. Hence, both fail to rescue the child, but only Lisa incurred some actual cost in trying to do so. It seems plausible that her having taken on this cost should count in her favor, morally speaking. That is, the actual cost that a person incurs in an attempted rescue would seem to function as a factor that mitigates increases in required cost that result from her earlier failures to assist. If, on the one hand, she fails to save the child due to

\footnotetext{
${ }^{7}$ We are grateful to an anonymous reviewer for drawing attention to this implication.
} 
factors beyond her control (or to factors for which she cannot plausibly be held responsible), then this should not increase her required cost to save the child later on. When an agent is in no way at fault for having failed to assist some person at an earlier time, it seems unfair that her duty to assist that person should require that she take on more cost at a later time to save the person. If, on the other hand, Lisa tries to save the child but her efforts are insufficient for reasons for which she can be held responsible, then this may reduce but not eliminate entirely the increase in required cost to save the child later on. ${ }^{8}$

\section{Imposing Cost}

Our discussion of the increase in Bill's required cost may seem somewhat beside the point. After all, Bill seems to show such disregard for the child's welfare when he fails to press the button that it seems extremely unlikely that he, a non-repenting person, will be moved to perform his duty at $t_{3}$, which requires that he take on more cost than the initial duty he failed to discharge at $t_{1}$ required of him. As noted above, however, Bill may have not pressed the button (for whatever reason) with the intention of assisting later, even if he knew he would thereby incur greater cost. In any case, we can consider the situation from another angle, by asking about the amount of cost that others can impose on Bill to realize the purpose of saving the child. There are two ways in which achieving this might involve imposing cost on Bill. The cost might be imposed on him in order to compel him to save the child, or the available means of saving the child may have as a consequence that this cost is imposed on him.

Different agents can become liable to the imposition of different levels of cost, depending on different morally relevant characteristics that they possess or lack. For Bill to be liable to bear a certain amount of cost means that his rights would not be violated should that cost be imposed on him. ${ }^{9}$ How much cost one would be permitted to impose on the agent that is the target without violating his rights seems to depend in large measure on how much cost this agent would be required to bear in the first place. For example, it seems impermissible for one agent to compel another to do $\mathrm{X}$ unless that agent is morally required to do $\mathrm{X} .{ }^{10}$ This is

\footnotetext{
${ }^{8}$ It may not even reduce the increase in cost if she is at fault for having failed to save the child earlier, even if she ended up taking on more cost than was required of her.

${ }^{9}$ We shall use the notion of liability in this article in Jeff McMahan's sense: a person is liable for the imposition of cost at level $\mathrm{X}$ if imposing $\mathrm{X}$ on her would neither wrong her nor violate her rights. Jeff McMahan, "The Basis of Moral Liability to Defensive Killing,” Philosophical Issues 15 (2005): 386-405.

${ }^{10}$ See, for example: Helen Frowe, "Killing John to Save Mary: A Defence of the Moral
} 
why it would be impermissible to severely injure another person (call him John) to save the child when John has played no role in her plight and is nonculpably ignorant of the fact that he can do anything to save her-John would not be liable for the imposition of cost of this magnitude and his rights would be violated if it were imposed on him. There may of course be cases where it is permissible to impose on an agent cost for which he is not liable (i.e., permissibly violate his rights) so long as the good that can thereby be achieved is sufficiently large, but that is a separate matter. ${ }^{11}$

There may be some exceptions to the alleged symmetry between an agent's duty to bear cost and the permissibility of imposing that cost on him. For instance, some may maintain that it is permissible to redirect a trolley towards one person to save five, but reject the idea that the single person would have a duty to bear this cost to save the five. On this view, he would not be required to divert the trolley towards himself to save the five, and he could perhaps also impose a cost on you to prevent you from doing so. But there are differences between cases that involve the diversion of threats and other cases, and these differences explain why it may be plausible to maintain the symmetry claim for cases that do not involve the diversion of threats. For example, when we impose cost on the single person by redirecting a trolley, it might be thought that we are not initiating a new threat. ${ }^{12}$ Moreover, the permissibility of imposing cost on the single person depends uniquely on the possibility of redirecting the trolley to save a larger number of people. If all else is equal (in the sense that the trolley is heading towards five and there is a person on the other track), but we are unable to redirect the trolley, we may not do something else to the single person in order to save the five (for example by pushing him onto the track to block the trolley from continuing towards the five).

There is no similar dependence on the availability of particular means in order for it to be permissible to impose cost on Bill to save the child in the case that we have been considering. In this case it is simply a question of the maximum level of cost that permissibly can be imposed on Bill without violating his rights. This cost can be imposed in a range of different ways, because he has rendered himself liable for the imposition

Distinction between Killing and Letting Die,” in Joseph Keim Campbell, Michael O’Rourke, and Harry S. Silverstein (eds.), Action, Ethics and Responsibility (Cambridge, Mass.: MIT Press, 2007), pp. 47-66; Victor Tadros, The Ends of Harm (Oxford: Oxford University Press, 2010); and Gerhard Øverland, "Forced Assistance," Law and Philosophy 28 (2009): 203-32. We discuss a possible exception to this general claim below.

${ }^{11}$ We return to the relevance of this possibility below.

${ }^{12}$ See Fiona Woollard, "Doing and Allowing, Threats and Sequences," Pacific Philosophical Quarterly 89 (2008): 261-77, for discussion of the complex issue of individuating threats. 
of that cost by having failed to assist at moderate cost at an earlier time. And it is because this cost can permissibly be imposed on Bill in a range of different ways that it also seems plausible to hold that there is symmetry between the cost it is permissible to impose on Bill and the cost Bill would be required to bear in order to save the child.

It seems that quite a significant level of cost could forcibly be imposed on Bill to save the child if the situation is fully transparent to him and it has become clear that he has failed to press the button at so little cost to himself or others without forming the intention to save the child at a later time-we could injure him severely if this would compel him to press the button if pushing it were all it took to save the child from drowning. And it does not seem as if we would have to compensate him after the fact (as we would if we were instead engaging in an impermissible violation of his rights).

What about a situation where Bill is not the only one who can save the child at very little cost? Imagine that the situation is fully transparent and there are five bystanders who can save the child at $t_{1}$, yet all of them simply fail to do so. Could any one of them be injured to force him to save the child at $t_{3}$ if this is necessary to save the child? A share of the cost could surely be imposed on each of them if that share was below what would be required of each. But what if it is only possible to impose the entire cost on Bill alone? Would it be unfair to Bill to do this? Perhaps, but imposing all of the cost on Bill nevertheless seems permissible, and would not seem to violate his rights, so long as the cost imposed does not exceed the total of what he and the others were required to bear. If the full cost of saving the child were imposed on Bill, we might think that he would be entitled to seek compensation for his sacrifice from the other bystanders who failed to assist, since they did not bear their fair share of the cost.

The use of coercive force may of course bring additional costs. These costs must always be considered, since they militate against its employment. One cost of the use of coercion in the case we are considering may be the psychological hardship that Bill suffers upon being forced to do something that he doesn't want to do. In such a case, there could be a reduction in the level of cost that permissibly could be imposed on Bill as compared to Bill's required cost. Hence, it could be impermissible to impose as high a cost on a person as he would have had a duty to bear in the first place. Thus, if Bill had a duty to bear 15 cost units, the cost others were permitted to impose on him could be only 15-q, where the constant q denotes the costs associated with coercion.

The manner in which our efforts to coerce impose additional costs (to Bill and others) should also be considered. The magnitude of such addi- 
tional cost might in part depend on Bill's reaction to our use of force. If Bill's reaction is completely unreasonable-he simply resents our compelling him to do what he recognizes to be a moral requirement-we might consider this additional cost to be of little or no moral importance. On the other hand, if Bill's reaction is reasonable, as it might be if he were unaware of the child's plight and consequently resented our seemingly gratuitous coercive intervention in his life, then it seems that the extra cost Bill associates with our using force against him should be taken into account, so that the overall cost imposed on him does not exceed his required cost.

As Garrett Cullity has noted, when we refuse to assist another person in severe need, we need to provide a reason for this refusal. ${ }^{13}$ It doesn't seem coherent for the agent to say: "yes, it is true that I am required to take on moderate cost to save the child, but you cannot impose it on me to achieve the purpose of saving the child when I am unaware of the situation, or when I am aware of it but unwilling to take it on." People should accept that the necessary cost can be imposed on them, as long as this is no more than the level of sacrifice that they are required to make (when the costs to them of such coercion are duly taken into account).

When an agent observes that a child is drowning, we demand that he take on the necessary cost to save the child as long as this does not exceed the required cost. That is why we will blame him if he fails to do so during the period in which he can. But suppose that he is unable to save the child, or doesn't see that the child is at risk of serious harm. Shouldn't we then be permitted to impose as much as the required cost on him, if doing so would be necessary to save the child? Recall that it could be necessary to impose the cost on him, either as a side-effect of saving the child, or directly if we need to use him to save the child (this would be in contrast to the trolley diversion case discussed above). And he ought to accept that as much as the required cost be imposed on him when he is unable to discharge his duty and when this is necessary.

Clearly, if our use of force against him takes place and he is caused to suffer some minor injury, he might protest. But when the situation later becomes fully transparent to him, he should accept that the use of force was justified, so long as this did not cause him to take on more cost than he was required to at the time. In most practical contexts, of course, the forms of compulsion employed to ensure that people discharge their duties to assist will not ordinarily take the form of injuring them. They will rather be through more mundane measures such as compelling them to contribute to taxation and transfer schemes.

\footnotetext{
${ }^{13}$ Cullity, The Moral Demands of Affluence.
} 
In the case under discussion, it has been assumed that we, who are in a position to impose cost on Bill, could not save the child by taking on the cost ourselves instead. If we could, we would presumably be required to do so. But suppose that we could make the sacrifice ourselves. Would we nevertheless be permitted to impose on Bill a share of the rescue cost, in such a case that it could be divided? Surely we could if the total necessary cost for us would exceed our required cost (in which case we would lack a duty to take on the necessary cost ourselves). We could then be permitted to impose the extra cost (the amount of the necessary cost that exceeds our required cost) on Bill as long as this cost does not exceed his required cost. ${ }^{14}$ It is important to emphasize that the total cost to Bill should not exceed his required cost. So if the cost we directly impose on Bill by coercing him to save the child is 10 units, and the cost of the rescue mission itself imposes 15 additional units, then our intervention is justified only if his required cost at that time is 25 units. ${ }^{15}$

The increased cost that it seems permissible to impose on people (without thereby violating their rights) who fail to assist others in extreme need is a good indication of the increase in required cost for them resulting from such failure. If we are permitted to impose 10 cost units on Bill to secure the child's rescue without violating his rights, then Bill is required to take on 10 cost units to save the child. If Bill could save the child by pressing a button at extremely low cost, knows this, but prefers instead to watch the child drown, it seems permissible to impose quite a lot of cost on Bill to save the child without violating his rights. How much cost? It is not clear, but probably a great deal more than he was initially required to take on, summed with his assistance shortfall. When the necessary cost is close to zero, summing his initial required cost with his duty shortfall would only amount to double the initial moderate cost. This seems much too lenient on Bill when he has acted with such wanton

\footnotetext{
${ }^{14}$ If the necessary cost to us were less than our required cost, we have no settled view on whether or not it would be permissible to impose some of this cost on Bill to avoid shouldering it ourselves entirely.

${ }^{15}$ In our treatment of these issues we do not wish to imply that there is no difference between the cost that we could impose upon an agent as a means of getting her to save another, and the cost we can impose on her as a side-effect of ourselves saving the person in need. In the case in which we impose cost on a person as a means of getting her to save someone, that person presents a causal opportunity to save the person in need, in the sense that we could not save the person in her absence. This is not so in the case where we impose cost on someone as a side-effect of saving the person in need ourselves. On some accounts, this may make it permissible to impose more cost on people we harm as a side-effect than on people who present us with causal opportunities to confer benefits. See Gerhard Øverland, "Moral Obstacles: An Alternative to the Doctrine of Double Effect,” Ethics 124 (2014): 481-506, and Jonathan Quong, “Killing in Self-Defense,” Ethics 119 (2009): 507-37, for discussion.
} 
disregard for the welfare of the child.

One way to illuminate how much cost could be imposed on Bill in this scenario would be to consider whether we should use force against him or another person (Anne) who nonculpably caused the child to end up in the river, but who now is unaware of the child's situation. Anne is what we shall call an innocent contributor to the child's plight. In this scenario, it seems preferable to impose cost on Bill, who has culpably failed to assist, rather than on Anne. After all, Bill fails to assist when he knows that he can at very little cost, without making a credible commitment to saving the child later. By contrast, Anne has merely been unlucky - in the wrong place at the wrong time-and as a consequence, causally contributed to the child's plight. Clearly, this would not be of much significance for those who deny that any additional force can be used against innocent contributors. ${ }^{16}$ But most people do seem prepared to accept that quite a lot more can be done to innocent contributors than to innocent bystanders; and many hold that it can be permissible to kill innocent contributors to save their victims, provided that the magnitude of their contribution is sufficiently large. ${ }^{17}$ If you now accept that we should rather impose cost on Bill than on the innocent contributor, then whatever cost you think permissible to impose on an innocent contributor to save the child would be permissible to impose on Bill as well.

Another way to illuminate how much cost we could impose on Bill when he is culpable would be to consider how we ought to respond if another person nearby-Alice-killed Bill to save the child. Would it be appropriate to blame Alice for having done so? We are not sure, and won't take a position on this here, but it doesn't seem obvious that she should be blamed. Nor does it seem obvious that it would be permissible to intervene to prevent Alice from rescuing the child (if the upshot of intervening would be the child's death and Bill's survival.) By contrast, it clearly would be permissible to prevent Alice from killing an innocent bystander in order to rescue the child, and to blame her if she made such an intervention.

It is important that in the case described, the degree of culpability of the agent who refrains from assisting is transparent to third parties. This is often not the case in the real world. We do not always (or perhaps not even ordinarily) know why someone fails to assist another person. When

\footnotetext{
${ }^{16}$ See, for instance: Michael Otsuka, "Killing the Innocent in Self-Defense," Philosophy \& Public Affairs 23 (1994): 74-94; Jeff McMahan, "Self-Defense and the Problem of the Innocent Attacker," Ethics 104 (1994): 252-90; and David Rodin, War and SelfDefense (Oxford: Clarendon Press, 2002), pp. 70-99.

${ }^{17}$ See, for instance, Judith Jarvis Thomson, "Self-Defense," Philosophy \& Public Affairs 20 (1991): 283-310, and Quong, "Killing in Self-Defense."
} 
we do not know the reason for someone's assistance failure, we cannot simply assume that his failure is culpable. The level of cost for which bystanders are liable is extremely sensitive to their beliefs, intentions, and dispositions. If Bill were even a little bit confused about the situation when he encountered the child and was therefore unsure whether pressing the button would suffice to save her, then the cost we would be permitted to impose on him as a means of compelling him to save the child without violating his rights would be reduced quite significantly.

\section{Deferring Performance}

When it is obvious to a person that he can save another in extreme need at very low cost and he fails to do so, there are two possible explanations for his conduct. It may be that he simply disregards the other's welfare. On the other hand, it may be that while he recognizes the importance of the person's welfare and acknowledges a duty to assist her, he chooses not to do so during the interval $t_{1}-t_{2}$.

In this second scenario, Bill does nothing wrong when he fails to assist the child during the initial period so long as we think that it is at his discretion to save the child later, even if it will then be more costly for him to do so ${ }^{18}$ He would in this case be deferring performance of his duty, and his failure to assist would not be culpable, so long as this delay imposes no additional cost on the child. Consequently, Bill would not be a culpable bystander at $t_{3}$, when his assistance has become more costly. What implications would this have for the cost that could permissibly be imposed upon him without violating his rights (and, a fortiori, the cost he would have a duty to take on to save the child)?

We need to consider why he would choose to defer the performance of his duty under these circumstances. If all else is equal to him, then his choice can only be explained by a lack of rationality on his part. Why else would he choose to take on more cost later, all else being equal, for the same purpose that he can achieve at less cost now? (Recall that we are assuming that the situation, including the costs of saving the child at different times, is fully transparent to him.) Irrationality, however regrettable, is part of the human condition, and it is not obvious that we should consider Bill to be morally blameworthy for irrationally deferring the performance of his duty. Consequently, it may be that the cost that could later be imposed upon him to save the child would be significantly less than could

\footnotetext{
${ }^{18}$ Things would of course be quite different if a delay in saving the child increased the risk of harm to her, or caused her suffering in the intervening period (without any change in the cost to Bill). In this case, if Bill saves the child at $t_{3}$, then he does not fail in his duty to assist her, but he nevertheless wrongs her by failing to save her earlier.
} 
be imposed on an agent who culpably fails to assist at an earlier time.

Nonetheless, it also seems clear that Bill cannot reasonably claim that his required cost of saving the child remain at the same level as it was when he first encountered her. It seems unfair that the cost that has arisen as a result of Bill's failure be borne entirely by the child. Indeed, it seems that Bill could be compelled to bear a great deal of cost later on in this case. After all, he knew that he could save the child at very little cost, recognized a duty to save the child, and yet failed to assist her. Things would be different, perhaps, if Bill decides to save the child later while falsely assuming that the cost of doing so will not be greater than the cost of saving her now. The extent to which we should be lenient with Bill in this sort of scenario should depend on what he could reasonably be expected to know at the time when the opportunity to rescue the child first presented itself.

\section{Multiple Failures}

We have argued that if an agent fails to assist at $t_{2}$, he will incur a more demanding duty to $X$ at $t_{3}$. But what happens when the agent fails at $t_{4}, t_{5}$, and so forth? That is, suppose that there are successive moments when the agent believes that it is his last opportunity to save the child but on each occasion fails to do so.

One proposal for assessing an agent's required cost in this kind of scenario would be that it should increase as a function of the culpability of the failure and the magnitude of the assistance shortfall on each occasion. The necessary cost could stay low, and the agent could continue to fail at each opportunity. In that case, even a fairly trivial initial failure may end up generating a high level of required cost for the agent at a later time.

This proposal seems implausible when what is at stake for the person in need of assistance is relatively minor. For instance, suppose that you can assist someone at virtually no cost to avoid a minor setback-what is at stake is not the life of a child but whether Jill's suit will get wet and muddy. Bill can press a button that will ensure this won't happen. Bill continues to sit by the poolside having his afternoon tea. He does not care about the fate of Jill's suit, and might even find her struggle a rather entertaining break in an otherwise dull afternoon. Assuming that the button is within reach, however, he could save Jill's suit at almost no cost. Is it plausible to maintain that even after many repeated failures (which from Bill's perspective all look to be his last opportunity to prevent the harm), it could ever really become permissible to harm Bill significantly to save Jill's suit from getting wet and muddy without violating his rights?

We do not think that it could ever become permissible to harm him 
significantly for this purpose. However, this in no way undermines the ideas that we have been developing in this essay. Note that the cost Bill would be initially required to bear to save a person from getting a wet and muddy suit (if he is required to bear any cost whatsoever) is extremely small-all else being equal, he is probably not even required to get the arm of his own shirt wet for this purpose. And for this reason it is virtually impossible to enforce Bill's duty to take on cost to prevent Jill's suit from getting wet and muddy without exceeding his duty to bear cost in the first place. When it is possible, our view implies that imposing this very small cost on Bill to save Jill's suit is indeed permissible.

However, it seems reasonable that the duty to bear cost, no matter the number of failures, should not ordinarily exceed what is at stake for the person who is in need of assistance. The case discussed earlier in this essay involved a child's life. For this reason, multiple assistance failures could result in a culpable bystander having to take on a great deal of cost. But in the case involving Jill's suit, a great deal less is at stake for the person in need of assistance. Hence, while multiple failures could indeed increase what is required of Bill-it could, for instance, ultimately become permissible for Jill to redirect the water towards Bill and get his suit wet and muddy if this were necessary to protect her suit-Jill (or others acting on her behalf) could never do more than that to Bill without violating his rights, since this would exceed what is at stake for her. ${ }^{19}$

\section{The Openness of Assistance-Based Duties to the Poor}

When Peter Singer first invoked his famous pond case, his motivation was to get people to reflect on a rather different sort of case- the capacity to prevent serious harm to the poor abroad at relatively little cost. Singer appealed to intuitions about the required cost of saving a child at risk of dying who is right in front of you, and proceeded by arguing that the differences between your relation to this child and your relation to children dying of poverty-related causes abroad are not morally relevant. Consequently, he inferred that the required cost for ordinary affluent people to address the needs of poor children throughout the world is much higher than they seem to recognize, and that they should eliminate much of their ordinary expenditure and instead donate to poverty-relief organizations. $^{20}$

\footnotetext{
${ }^{19}$ We leave open whether there are some cases where the level of sacrifice can exceed what is at stake for the person in need. It seems possible in principle that a person who is fully culpable for failing to save a child's leg at nearly zero cost could later be required to sacrifice more than one leg to do so later on.

${ }^{20}$ Singer, "Famine, Affluence, and Morality”; also, Unger, Living High and Letting Die.
} 
Critics of Singer's argument have generally not challenged his claims about our duties in rescue cases, but have instead typically tried to establish that the analogical arguments on which these conclusions are based are flawed, since there are significant differences between children dying of poverty-related causes across the world and children dying right in front of you in a pond. ${ }^{21}$ One such disanalogy seems particularly relevant to our discussion here. In simple rescue cases involving children drowning in ponds, it seems that the person who comes across them has a duty to assist these particular children. It is questionable, however, whether or not we should understand the duties of affluent people to assist the poor abroad as duties owed to particular people. ${ }^{22}$ That is, just which poor people one chooses to assist is arguably at the discretion of the agents. Their duty is to do enough for some poor people, rather than some particular thing for any particular poor person. So a person who fails to assist a particular poor person overseas when he can do so at less than required cost has not failed in his duty to assist, even if he can no longer assist this particular person, so long as he remains in a position to assist some other poor people. This seems in contrast with the case that we have been considering-if Bill can no longer save the child, it seems that he has indeed failed in his duty to assist her.

This disanalogy between the cases seems important, since this essay has been framed in terms of the increase in required cost of saving a particular person whom you have a duty to save, and whom you earlier failed to save. Consequently it may seem that our discussion here is less relevant to the issue of our duties to the poor abroad. That is, there may be no particular person whom we have a duty to assist in the first place (and consequently no person whom we have failed to assist when we had a duty to assist her). We agree that there are important differences between the two cases. Nevertheless, our discussion may have some important implications for duties to the global poor as well. Note first that it is questionable just how open duties to assist the poor abroad are. Imagine that all affluent people today decided not to assist people in need abroad on the ground that they will provide their share of assistance later, with

\footnotetext{
${ }^{21}$ See, for example: Richard Miller, "Beneficence, Duty and Distance,” Philosophy \& Public Affairs 32 (2003): 357-83; David Schmidtz, "Islands in a Sea of Obligation," Law and Philosophy 19 (2000): 683-705; and Leif Wenar, "What We Owe to Distant Others," Politics, Philosophy \& Economics 2 (2003): 283-304.

${ }^{22}$ This difference is sometimes framed in terms of the distinction between perfect and imperfect duties. We avoid using this terminology, because there is no consensus on how this distinction should be understood, and thus it might easily invite misunderstandings. For discussion of the imperfect/perfect distinction, see S. Andrew Schroeder, "Imperfect Duties, Group Obligations, and Beneficence,” Journal of Moral Philosophy (2013), DOI 10.1163/17455243-4681020.
} 
the consequence that a great many people now die who could be saved at little cost. Is it plausible to say in this case that no one has failed in his duty to assist, since each person possesses only an open-ended duty to the poor, rather than a duty to particular poor people or currently existing poor people? It certainly seems sensible to say that the affluent are not doing enough for the poor right now. (And if we say this, we don't seem to be referring only to those affluent who are now dying and thus cannot claim that they will do their share in the future.)

In any case, our argument might have some application to global poverty even if we take for granted the underlying assumption regarding the openness of the duties of the affluent to the poor. Suppose, for example, that at one time interval, one affluent person is in a position to assist some poor people at relatively low cost. The person decides not to assist these people at this time. Here there are two possibilities: the failure of assistance is either because the affluent person simply disregards the welfare of the poor person, or because the person is sincerely committed to assisting other poor people at some point in the future. Let us assume that it is the latter type of situation. Suppose that the situation changes (either because of the circumstances of the affluent person or because of the situation of the poor people in need of assistance) such that it is now much more costly for the person to assist poor people than it was earlier. Note that we are assuming here that the affluent person did not initially owe a duty to any particular poor person.

Many studies of poverty suggest that it is intergenerationally transmissible. For example, a very good predictor of whether a child is going to be poor is whether or not her mother is poor. In that case, it may be that the failure of people now to address the poverty of present-day young people will play some role in the explanation not only of the poverty of these people at a later time, but of the poverty of altogether different people later on (their children). During the interval $t_{1}-t_{2}$, there might be a poor young woman who needs assistance. At $t_{3}$ it may be that that poor woman and also her poor children all need assistance. And it may be that the failure to provide assistance during $t_{1}-t_{2}$ is a factor that has given rise to an increased cost of assistance at $t_{3}$.

It is not obvious that at this later time when it has become more costly for the affluent to discharge their duty to the poor, they can now appeal to the (increased) cost of assisting the poor as an excuse for making only a small impact on poverty. Here too it can be pointed out to them that they had an opportunity to provide assistance earlier when it was not costly for them to do so. They simply decided not to avail themselves of that opportunity. By hypothesis, they were within their rights to decide not to assist during $t_{1}-t_{2}$, but it does not follow from this that they are 
now entitled to reduce the assistance that they provide to the poor at $t_{3}$. In what sense are they reducing the assistance they provide? Not, presumably, in the sense that their required cost of assisting is less than it was earlier. It is reduced in the sense that their taking on that level of cost would do a great deal less for the poor than the same cost would have achieved had they acted previously.

Further factors about the agent and the situation are relevant to judging this sort of case. For instance, if the very reason it has become more costly to assist at the later time is because assistance was not offered at the earlier time, this may make a difference to what is later owed. What is known or could reasonably have been foreseen by the agent who defers performance of his duty is also important, especially if it can be known at the time at which the deferment of the duty occurs that the value to the poor of assistance will diminish over time.

While duties to assist the poor may not be owed to particular poor people in the same way that a promise is owed to the promisee or a duty to rescue is owed to the child in the pond case, failing to assist on one occasion may nevertheless leave a normative mark. It does not increase what the duty-bearer is required to do for them, but it can increase the cost that the duty-bearer can be required to shoulder for this purpose. Consequently, even if we cannot determine with any precision the assistance shortfall of affluent people, the fact that they fail to assist indicates that their duty to bear cost to help protect the global poor is likely to increase. If they fail to assist now, they should accept that they may be required to take on more cost for the purpose of assisting the poor in the future. If it turns out that discharging our duty to assist now will make more of an impact on poverty than if we act later, then deferring performance of the duty makes it the case that there is some extra burden that someone is going to have to bear later on. As more cost will then have to be borne (since the affluent did not discharge their duty), it seems fair that at least some of this cost should be borne by the affluent who have failed to assist. They cannot leave the poor to bear the entire cost to which the earlier failure of the affluent has given rise.

There are further features to the case of global poverty that make it more complex. Recall that the magnitude of the assistance shortfall is determined by the difference between required and necessary cost, and mitigated by the magnitude of actual cost that the agent bears. This implies that the degree to which the required cost of affluent people to address poverty will depend in some measure on what cost they actually bear in the first place. Many countries provide assistance overseas through the tax system. The closer the actual cost that the affluent bear through the tax system is to the required cost, the less will be the increase 
in required cost later on.

There is reasonable normative uncertainty about the required cost to assist the poor abroad. This makes it hard to assess the magnitude of different agents' assistance shortfalls. We cannot try to resolve these complicating issues here. We only raise them in order to indicate some limits to the account presented here for issues of global poverty and the way in which affluent people's responsibility to bear cost can increase as a consequence of their earlier failures to assist.

Finally, it has been implicit in our discussion that the holdings of the person who is in a position to assist rightfully belong to him, but it is questionable whether we can say the same thing about wealth that is in the possession of affluent people in the world today.

\section{Conclusion}

In this essay, we have argued that it cannot be inferred from the fact that assistance-based duties are relatively undemanding that the duties of those who have failed to assist at some earlier time are undemanding as well. Like duties based on having contributed to hardship, the duties to assist of those who have earlier failed to assist can be quite demanding indeed-and can be enforced through the proportionate use of force. We concluded by noting some of the potential implications for the requirements imposed by assistance-based duties to the poor abroad. ${ }^{23}$

*Center for Moral, Social and Political Theory, Australian National University

christian.barry@anu.edu.au

**Center for the Study of Mind in Nature, University of Oslo

g.e.overland@csmn.uio.no

\footnotetext{
${ }^{23}$ Earlier versions of this paper were presented at seminars at the Australian National University, the Goethe-Universität in Frankfurt, and Universidade Federal do Rio de Janeiro (UFRJ). We are grateful for comments received from participants in these seminars, and also to Tom Dougherty, Luara Ferracioli, Bob Goodin, Robert Kirby, Ole Koksvik, Seth Lazar, Alejandra Mancilla, Darrel Moellendorf, Holly Lawford-Smith, and two anonymous referees for written comments on earlier versions. We also gratefully acknowledge the financial support of the Australian Research Council and the Research Council of Norway.
} 